\title{
A Survey of Inlet/Engine Distortion Compatibility
}

David N. Bowditch and Robert E. Coltrin Lewis Research Center

Cleveland, Ohio

Prepared for the

Nineteenth Joint Propulsion Conference cosponsored by the AIAA, SAE, and ASME Seattle, Washington, June 27-29, 1983

\section{LIBRARY COPY}

UEC I 3983

LANGLEY RESEARr: LIBRARY, NASA HAHETON, VIRGINIA 


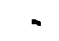




\section{A SURVEY OF INLET/ENGINE DISTORTION COMPATIBILITY}

David N. Bowditch and Robert E. Coltrin

National Aeronautics and Space Administration

Lewis Research Center

Cleveland, Ohio 44135

\section{Abstract}

The history of distortion analysis is traced back to its origin in parallel compressor theory which was initially proposed in the late fifties. The development of this theory is reviewed up to its inclusion in the complex computer codes of today. It is found to be a very useful tool to guide development but not quantitative enough to predict compatibility. Dynamic or instantaneous distortion methodology is also reviewed from its $\approx$ origins in the sixties, to its current application $\rightarrow$ in the eighties. Many of the requirements for interpreting instantaneous distortion are considered and illustrated. Statistical methods for predicting the peak distortion are described, and their limitations and advantages discussed.

Finally, some Reynolds number and scaling considerations for inlet testing are considered. It is concluded that the deterministic instantaneous distortion methodology combined with distortion testing of engines with screens will remain the primary method of predicting compatibility for the near future. However, parallel compressor analysis and statistical peak distortion prediction will be important tools employed during the development of inlet/engine compatibility.

\section{Introduction}

Ever since the introduction of turbine engines with axial flow compressors for propulsion of military aircraft, airframe/propulsion system compatability has been a problem. The intensity of the investigation into the distortion aspects of this problem has varied over the years for a number of reasons. The early turbojets with their simpler compression systems were more tolerant of distortion than at least the early turbofan engines. When these engines were combined with the relatively short, supersonic F111 inlet system, serious enough compatability problems were encountered that the next generation of military aircraft (F14, F15, F16, F18) were driven to relatively conservative inlet designs to avoid distortion compatibility problems. This has beer highly successful. However, after a decade of relative success, new propulsion installation requirements are making it highly desirable to use shorter offset inlet ducts on future high performance aircraft. As a result, it will be more challenging in the future to avoid propulsion stability problems associated with distortion. It, therefore, appears appropriate to review the current distortion methodology, and its origins.

This paper will attempt to go back and trace the origins of much of the distortion methodology in use today. The response of the turbine engine to steady state distortion will be considered initially and the concepts inherent in today's dynamic and instantaneous distortion methodology will be discussed. Some recent statistical procedures for significantly reducing the reauired resources necessary for dynamic distortion analys is will be considered, and finally the application of these procedures to inlet testing will be treated.
Turbine Engine Distortion Response

Turbine engine response to distortion is intimately tied to the response of its compression system. Therefore, the effect of distortion on the stall line or stall margin of the compression system will be of primary concern. Distortion can include many flow parameters including total and static pressure, velocity, flow angle, and temperature. While all these distorted flow properties are acknowledged, distortion is almost exclusively considered in terms of total pressure and temperature. Not only are total pressure and temperature easily measured, but the profiles of the other parameters are closely related to the profiles of pressure and temperature. Thus, the pressure and temperature profiles are characteristic of more than their own distortion when compared for similar geometries. In the following discussion, the effect of steady state distortion on compression systems will first be considered. Then the time varying characteristics of distortion and their effect on engines will be discussed.

\section{Parallel Compressor Modeling}

For circumferential distortion where one or more angular segments of a simple compressor operate with lower inlet pressure than the remainder, the concept of parallel compressors is quite applicable. The concept was first proposed in 1959 and extensively explored for simple compressors in Ref. 2, from which Figs. 1 and 2 were extracted. The theory assumes that two identical compressors with characteristics equivalent to the undistorted performance of the study compressor, must deliver flow to an equal exit static pressure while one accepts spoiled flow and the other unspoiled flow. Figure 1 shows the effect on the surge delivery static pressure of the angle of the spoiled sector. As the angle is increased, the surge delivery static pressure drops to a value equivalent to the entire compressor operating with the lower pressure spoiled flow. For this case, a critical angle of about $60^{\circ}$ of spoiled flow is required to reach the lower level and that angle represents the time the rotor blades must remain in the spoiled region to reach a steady response to the lower pressure. For lower angles they can sustain a higher pressure ratio (or loading) without stall. Therefore, for spoiled angles greater than $60^{\circ}$, the steady operation of the parallel compressor accepting spoiled flow sets the stall limits for the compressor pair. This critical angle, or its equivalent, is incorporated into a number of stall parameters. Figure 2 presents a similar plot for multiple spoiled sectors and the same critical angle of about $60^{\circ}$ appears to apply again. The critical angle is usually determined in compressor distortion testing. It can be increased through compressor design. Newer compressors with higher aspect ratio blading tend to have Targer critical angles and, therefore, an improved distortion tolerance.

Parallel compressor modeling can also be used to investigate the effect of temperature distor- 
tion. Here, the parallel compressor that accepts the higher inlet temperature (spoiled) region operates at a lower corrected speed, and thus cannot produce as much pressure ratio as the compressor with the cooler inlet temperature. Figure 3 obtained from Ref. 3 presents a comparison of the actual loss in pressure ratio at stall $\triangle P R S$, to the value predicted by parallel compressor analys is for a 385 turbojet.

$\Delta P R S=1-\frac{\left(\mathrm{P}_{3} / \mathrm{P}_{2}\right) \text { Distorted }}{\left(\mathrm{P}_{3} / \mathrm{P}_{2}\right) \text { Clean }}$ Constant Speed

The agreement is quite good for combined temperature and total pressure distortion. This is probably due to the limited circumferential spreading that is possible in an axial compressor. When radial distortion is considered, its effect cannot be predicted with parallel compressor modeling due to the ease of radial readjustment and interaction of the spoiled and unspoiled flows. The combined effects of radial and circumferential distortion are even more difficult to treat.

So far, only single spool compressor systems have been considered. Modern compression systems normally combine fans and compressors on multiple spools, making their interaction complex and more difficult to predict. A perspective on this can be obtained by considering Fig. 4 from Ref. 4, which presents the propagation of the spoiled sector through a TF 30 compression system. The indicated stations are 2, compressor face, 2.3 low compressor inlet, 3 high compressor inlet, and 4 compressor exit. The cross hatched spoiled regions represent lower than average pressure and velocity or higher than average temperature. The results are for a $180^{\circ}$ total pressure distortion which also has lower than average velocity in the spoiled sector. As the total pressure distortion propagates through the system, it becomes radial at some angles and finally splits into two parts. While there is no temperature distortion at the inlet, a temperature distortion is generated by the compression system operating on the pressure distortion. It does not appear to be directly related to the low pressure region even though it originates from that distortion.

The complexity of the distortion effect is obvious. Each compression component is presented with a different distortion as its character changes. Components have been observed to both increase or decrease the distortion and generate varying amounts of temperature distortion. Therefore, prediction of the stability of an entire complex compression system is beyond simple parallel compressor modeling. However, used individually on each component, it can provide insight into weak links and solutions to stability problems.

To provide further understanding of multiple compression systems, complex compressor models have been devised and implemented on computers. Features of these models, presented in Fig. 5, include the capability of over 30 parallel compressors, radial two dimensional flow effects associated with the fan splitter, dynamic blade response to distortion, engine induced flow redistribution ahead of the fan, cavity crossflows, and compressor variable geometry. These compressor models have been very useful in predicting more tolerant configurations or critical stages. As such, it provides a valuable tool for compressor development. However, it is not auantitative enough to use for prediction of distortion tolerance.

While a number of tools exist to indicate the way to improve compression system tolerance to distortion, none are reliably accurate. As stated on Fig. 6, parallel compressor theory provides the basis for many of those tools which give significant insight into distortion effects and valuable guidance during compression system development. However, the interaction of radial and circumferential distortion is not well understood. Also, complex compression models are reauired for turbofan engine systems, and stability can be significantly affected by dual spool engine rematching which is difficult if not impossible to include. Therefore, for the near future, compatability programs will continue to use empirical parameters such as $K_{D}$ and $\triangle P R S$.

\section{Dynamic Distortion}

\section{Turbulence}

While it may have been suspected prior to that time, the first time that it was generally agreed that fluctuating characteristics of distortion caused engine stall occurred during analys is of an early 1960's AEDC test of a $J 93$ engine with the B70 inlet. Engine stalls that could not be attributed to steady state distortion were suspected of being associated with inlet turbulence. This led to the development of some of the distortion simulators reported in Ref. 5 and shown in Fig. 7. The screen simulator in the upper left of the figure is the traditional method of generating a steady total pressure distortion in front of an engine by utilizing screens. This is still the recognized way to assess an engine's distortion tolerance. The simulator in the upper right used a variable plug in a venturi to create a shock system strong enough to create transient boundary layer separation with resulting turbulence in front of the engine. This successfully stalled the engine with nominal time averaged distortion at the compressor face, thereby demonstrating the ability of turbulence to cause compressor stall. This concept was later extended to simulators that reproduced the inlet geometry more faithfully. Turbulence in the 60's time period was measured in terms of its average root mean square, RMS, level over the compressor face. As a result, distortion parameters acquired the added complexity of RMS level in addition to the normal steady state distortion parameter. Correlations were generated, indicating that the engine could withstand less time averaged distortion if the turbulence level was higher. The correlations were highly configuration dependent and the values for one installation didn't necessarily apply to a second. This indicated the physical phenomena of turbulence was not well understood.

\section{Instantaneous Distortion}

By the later 1960 's, turbulence was producing unsatisfactory correlations, and it hegan to be associated with time varying or instantaneous distortion. This was proposed in 1969 in Ref. 6. The concept of instantaneous distortion introduces an entirely new set of interesting and expensive problems. Its measurement requires a 40 or 48 tube rake as shown in Fig. 8 , which contains a dynamic transducer in each tube to measure the absolute value of the time varying pressure. Each 
produces a pressure time history such as those shown on the figure's upper right which must all be sampled at the same moment of time to obtain an instantaneous total pressure pattern. This pattern can be reduced to an instantaneous value of the distortion parameter. Doing this at many increments in time produces the dynamic variation of the distortion parameter with time as presented at the lower right of Fig. 8. A peak in this parameter that exceeded the engine's distortion tolerance just prior to stall was shown to be the characteristic of turbulence that caused engine

stall. Full scale, each of the 40 dynamic pressure traces must be sampled up to 1000 times per second so that a minute or two of data reauires analysis of about half a million words of data. This is obviously expensive.

Distortion conditions are presented in Fig. $9^{7}$ which caused a 385 engine to stall during operation behind an axisymmetric inlet at Mach 2.6 and five degrees angle-of-attack. The engine stalled after several minutes of steady operation at fixed conditions, indicating the cause was associated with a random transient increase in distortion. The distortion is highly circumferential in nature, with a high dynamic level, particularly in the region of higher total pressure gradient between the high and low pressure regions. The steady distortion is 0.178 in terms of average minus minimum over average total pressures which corresponds to 0.10 for the distortion parameter presented in $\mathrm{Fig} .10$. The maximum instantaneous distortion occurring just prior to stall is also presented, and has a distortion parameter value of 0.155 . This exceeded the measured engine tolerance of 0.145 , and demonstrates the ability of the instantaneous distortion concept to explain the ability of turbulence to stall an engine in terms of its measured tolerance to steady state distortion.

The most direct way of determining the variation of instantaneous distortion with time is to digitize the 40 or 48 dynamic pressures at the compressor face, and compute distortion contours and/or an engine distortion parameter. This is quite expensive, due to the volume of data to be processed, and results are not usually completed until weeks or months after test completion. Several alternate ways have been developed. Analog distortion parameter calculators have been developed by several researchers, 8,9 and greatly reduce computational expense. Another major advantage is their on-line capability to produce real-time results, permitting assessment of an inlet configuration during a wind tunnel test. However, analog calculation procedures can limit the complexity of the distortion parameter to be analyzed and do not have the capability to generate the engine face pressure contour at one peak distortion time instant. Therefore, hybrid schemes have been developed to capitolize on the strengths of both analog and digital procedures. Probably the best hybrid system has been developed by the Air Force, 10 which monitors the time varying distortion with a large analog system to identify the distortion peaks, and then uses the digital computer to obtain total pressure profiles at the peak distortion time instant. However, this system is not currently portable, and results are usually obtained significantly after test completion.

The dynamic character of the distortion requires the consideration of new effects. How high of a frequency needs to be considered? When should filtering be done? Are there dynamic effects other than distortion variation? The highest frequency that must be considered is determined by how fast the engine can respond to a distortion peak. This is addressed in Fig. 11 from Ref. 11 where the predicted loss in stall pressure ratio, $\triangle P R S$, due to dynamic distortion is presented for a time period just prior to an engine surge. This data was for a drift stall of a 385 engine operating behind a supersonic inlet in the NASA $10 \times 10$ Foot Supersonic Wind Tunnel. To assure that the stall was caused by an extreme value of the random dynamic distortion, inlet geometry and flow conditions were changed in steps until a stall occurred after several minutes of stationary conditions. For this case, the raw dynamic pressure was smoothed with sliding averaging times corresponding to $0.25,0.5$ and 1 rotor revolution. The available stall margin of 0.079 is also presented for comparison. In theory, if the loss in stall pressure ratio, $\triangle$ PRS, exceeds the available stall margin, the engine should stall. Therefore, the 0.25 rotor revolution averaging time is obviously not long enough since the limit is exceeded many times for relatively long periods without inducing engine surge. The half revolution averaging time still leaves many peaks exceeding the limit, however, a one rotor revolution averaging time reduces ali the peaks below the limit. While the distortion peak causing surge is not clearly identified, the proper averaging time appears to fall between a half and one rotor revolution. Data from other dynamic distortion engine testing and flight testing have been similariy reduced with the same result. Whether it's a half or one rotor revolution probably falls well within the other approximations in the method.

Whether the dynamic pressures or the calculated parameter should be filtered is considered in Fig. 12, also taken from Ref. 11. Here, another drift stall is processed with filtering (or time averaging) applied at the input (dynamic pressure signals) or output of the calculation of time varying loss in stall pressure ratio, $\triangle P R S$. The output filtered data is generally higher than $\triangle P R S$ calculated from filtered dynamic pressures and the two are clearly not eauivalent. However, since the engine cannot respond to the higher frequencies, the input pressures should be filtered, making the dashed curve the correct one.

Although not often considered, the compressor face averaged total pressure varies with time during dynamic distortion. This is considered in Fig. 13 from Ref. 12, where the surge margin used by time varying distortion is compared to the available surge margin for conditions of (1) steady inlet pressure and (2) the actual time varying inlet pressure. The time averaged available surge margin is the normal steady value for the engine. The dynamic available surge margin was determined by subjecting a dynamic engine simulation to the measured dynamic variation in total pressure to determine the resulting time variation in compressor pressure ratio and concomitant time variation in surge margin. The surge margin used, $\triangle P R S$, is also different because it uses the instantaneous face average pressure in determining the amount of surge margin used. The comparison presents significantly different results with the used margins exceeding the available value at different times for the two cases. While in this case the consideration of dynamic average total pressure is not dramatic, it has been suspected of being more important in some recent applications. 
Statistical Assessment of Maximum

\section{Instantaneous Distortion}

In an inlet engine compatibility program, the most important parameter to be determined is the peak instantaneous distortion that the inlet will deliver to the engine. This peak instantaneous distortion must be typically defined in terms of the engine derived distortion parameter, $K$. The magnitude of the most probable peak instantaneous distortion varies with time as shown in Fig. 14 . $K$ is the parameter of interest and is plotted in terms of the maximum, $K_{\max }$, ratioed to the steady state value $K_{5 s}$. As shown, the most probable peak value increases with time and approaches the long time limit asymptotically. However, the most probable peak is only one of a distribution of $\mathrm{K}_{\max }$ values that might be obtained for any given record time. These amplitude probability densities (APD) are shown in Fig. 14 at time $a$ and at time $b$. Time a represents $a$ statistically short time on the order of $50 \mathrm{~ms}$. For this short time, the APD is very wide and it would be possible to obtain peak values anywhere from the long time maximum on the high side to the steady state value or even below on the low side. Time b represents a statistically long time of several minutes. For this long time, the APD is very narrow and the value that would probably be found is much closer to the most probable peak. From this example, it can be seen that it is desirable to search out the peak value over a long period of time using the deterministic method of calculating the variation of instantaneous distortion with time. As pointed out before, the deterministic method is expensive and to use it for a period of minutes just adds to the expense. So for the past 10 to 15 years, several researchers $13-16$ have been pursuing methods of predicting the most probable instantaneous distortion peak over a long time period using statistical rather than deterministic methods. Several methods have been tried, some of which relate to the statistics of the parameter and some of which relate to the statistics of the pressures used to determine the distortion parameter.

Sanders ${ }^{17}$ has a comparison of three of the most prominent methods against a given data set. Figures 15 to 18 were taken from Ref. 17 and wil be used here to briefly explain the various methods. Figure 15 is the deterministic method that has been described earlier. It requires the full compliment (40-48) of steady state and dynamic pressure transducers at the inlet/engine interface, digital tape for the steady state recording, and analog multiplex tape for the dynamic recording. Later, the steady state and dynamic signals must be merged and instantaneous values of the parameter calculated. From this record length the peak value can then be determined.

\section{Jacocks}

Probably the first attempt to statistically predict peak instantaneous distortion was by Jacocks 13 . This method starts with a short time sample of the instantaneous distortion parameter calculated from a deterministic process and then uses Gumbel's extreme value statistics to extrapolate to the most probable peak for any specified longer period of time. Therefore, as shown in

Fig. 16, this method requires the same full complement of $(40-48)$ steady state and dynamic pressure probes at the inlet/engine interface and a continuous computation of the distortion factor. As shown in the figure, an analog distortion calculator (ADC) is normally used for this purpose as it can be readily used online. The output of the $A D C$ is sent to a peak detector which searches for the peak value of the distortion parameter over a given time interval. Similar peak values are obtained for a number of time intervals from the available record. Gumbel's extreme-value statistics are then applied to these recorded peaks to predict the most probable peak distortion for a specified longer time. Sanders 17 found that execution time on an IBM 370/165 for the Jackock's program was about three seconds for processing 60 peak values.

\section{Melick}

The Melick method 14 relates the statistical characteristics of the total pressure fluctuations to the statistical characteristics of the distortion parameter, and is shown in Fig. 17. A full compliment of steady state pressure measurements is required at the inlet engine interface for steady state distortion calculation but only a few dynamic probes are required. Filtered and unfiltered RMS leveis are required from each dynamic probe and can be recorded on a steady state data system. The ratios of the two RMS levels from each of several probes are averaged and used as an indicator of the power spectral content of the fluctuating pressures. Using this information with distortion index statistics built into the program, the RMS of the distortion parameter can be estimated. Combining the RMS of the distortion parameter with its calculated steady state value and by applying a form of extreme value prediction, the most probable peak value of the parameter is calculated. This method adapts well to online prediction during wind tunnel testing. Sanders 17 found the execution time for the Melick program to be about 3 seconds on an IBM $370 / 165$.

\section{Motycka/Stevens}

The Motycka method 15 was also compared by Sanders 17 . Stevens 16 has also reported on a method that is essentialiy the same as that of Motycka. There are minor differences, but for the purposes of this paper, they will be considered the same method.

The Motycka/Stevens method uses random numbers to synthesize the time variant inlet pressures and in turn uses these synthesized dynamic pressures to determine the time varying inlet distortion parameter. Figure 18 shows that this method requires a full compliment of steady state and dynamic pressure probes at the inlet/engine interface. More recently, some work has been done to reduce the number of required dynamic probes. 18 The output of each dynamic probe is sent to an RMS meter. An APD curve is generated for every probe using the RMS and steady state value with the assumption of a normal distribution. Random numbers are then generated and converted to pressure by scaling to the APD or cumulative APD. The equal time step between pressure values is scaled so as to be consistent with the engine freauency range of interest. For each probe location, a digital pressure-time trace is constructed. A synthesized distortion parameter-time trace is then constructed using the original deterministic method and the peak value is found for the time period of interest. Sanders 17 found that the execution time 
for the Motycka program was about 90 seconds (for 0.5 seconds of data) on the IBM $370 / 165$.

There are several nuances to each of these methods and the reader is cautioned to fully understand a method and its limitations before it is applied.

\section{Comparison of Results}

In Ref. 17, Sanders presents a comparison of . the results from each of the statistical methods with results from the deterministic method for several sets of data. For Jacocks, which starts with a short sample of the deterministic results, the agreement was very good. Melick, which perturbs the steady state pattern based on the fluctuating pressure dynamics, obtained good agreement for some cases but not so good for others where the peak instantaneous distortion differed significantly from the steady state pattern. This latter type of distortion variation is often associated with flow separation and may not include the stationary properties required by the conventional statistics. The Motyka/Stevens method does better but also showed significant disagreement with the deterministic method for the same cases where maximum instantaneous distortion patterns differed significantly from the steady state pattern.

While the Melick methods agreement was poorest, its advantages of small computer time and fewer required pressure transducers from which only RMS must be recorded make it very attractive for application to early inlet parametric testing. Some criteria to identify conditions when poor agreement can be expected, such as nonstationary pressure signals, would greatly enhance its usefulness.

\section{Inlet Distortion Testing}

When testing inlets for performance and distortion, it is necessary to understand the expected sources for inlet distortion and interpret the results to account for scale effects. Some of the expected sources of inlet distortion are presented in Fig. 19. These were presented by Hall in Ref. 19 more as sources of inlet instability, but they serve equally well as sources of dynamic distortion. Supersonically, dynamic distortion is often associated with strong terminal-shock/boundarylayer interactions related to inlet overspeed or supercritical operation. Another source is associated with distortion of the forebody boundary layer so that it exceeds the inlet splitter height. This can be caused on the leaward side of the forebody by yaw or supersonically by the wing oblique shock as it sweeps the low energy flow down the side of the forebody and over the splitter plate of an underwing inlet. As the inlet is pushed back on the aircraft, ingestion of a vortex emanating from a wing discontinuity, or forebody corner, can also cause time varying distortion exceeding the steady state value. This is particularly true of over the wing installations which are considered for some VTOL aircraft. At high angle of attack, separation on the lower lip becomes a source requiring special lip shaping or auxiliary inlets to solve the problem. This problem is becoming more acute as the airframe aerodynamicysts are learning to control the aircraft at more extreme angles of attack and yaw. The remaining source of distortion dynamics is associated with transient separation in the subsonic diffuser. Many current aircraft have avoided this problem with relatively conser- vative diffusion rates and offsets between the inlet throat and the engine. However, future requirements appear to increase the desire to design inlets with higher values of diffusion and offset.

\section{Scaling Experimental Results.}

Inlet wind tunnel testing is rarely done at the appropriate scale, and if that is correct, then the forebody geometry is usually compromised in some manner. Therefore, it is important to understand the factors to be considered when extrapolating results to the flight vehicle, Fig. 20 . Reynolds number is usually considerably less than the full scale value, making boundary layer thicker when compared to the inlet dimensions. When testing with a forebody, the diverter is usually set out a distance corresponding to the increase in boundary layer thickness, which compensates for most of the difference. Bleed flows must also be increased to prevent encountering separation or other limits and a minor increase in distortion may be observed. Boundary layer or fully viscous analysis of the inlet internal flow can be used to estimate the reduction in boundary thickness and bleed to be expected in the flight vehicle while obtaining similar distortion levels to the model data.

Dynamic distortion assessment requires the consideration of frequency scaling of the dynamic pressure fluctuations. For a fult scale inlet, only those frequencies should be considered that are equal to or below the value to which a full scale engine responds. Therefore, it's necessary to know how inlet dynamic distortion power spectrums vary with scale, to determine the maximum frequency to be considered in assessing distortion from a small scale inlet test. Reference 20 considered this problem when comparing dynamic results from two wind tunnel models with flight data for a RA-5 aircraft. The assumption made here is that pressure fluctuations in boundary layers and acoustics scale such that a scale model will have the same overall turbulence (RMS) level but with a frequency shift that is inversely proportional to scale. Therefore, the pressure PSO from a subscale model will have a proportional amplitude and inversely proportional frequency shift relative to the pressure PSD of a full scale model. This maintains the square root of the area under the PSD's, which is the RMS level, at a constant value. Figure 21 presents power spectrums scaled to full size by multiplying the frequency axis by the model scale and dividing the power axis by the model scale for a total pressure on the upper outboard side of the engine face. In general, this scaling criteria appears good, although not perfect. Differences may be due to some of the errors that almost always creep into dynamic data reduction. These results indicate that frequencies to be considered for dynamic data reduction should he scaled linearly to the inverse of the model scale. Therefore, for an eighth scale model, frequencies to eight times the engine rotational frequency should be considered.

The final consideration for inlet testing to be discussed is the effect of the engine on measured compressor face distortion. During normal operation, the engine will induce nearly constant inflow velocity across its face. As shown in the botton of Fig. 22 from Ref. 21 , for a $180^{\circ}$ screen distortion, this induces a static pressure gradient around the compressor face similar to the total pressure distortion. This also induces the flow angles shown in the top of the figure, which are 
caused by the flow entering the low pressure region. This has a surprisingly small effect on the total pressure profile, and several researchers have concluded $1 \mathrm{ittle}$ or no effect. This may be true for distorted flow that is still relatively attached to the walls. However, there is suspected to be a larger effect of the engine in cases where the flow would be separated without the engine present. NASA Lewis and Oryden are currently planning to investigate this for the HiMAT inlet, which is relatively short with an offset diffuser. In cases where the engine inflow effect is suspected to be important, it may be necessary to simulate the effect on small models. This can be done by distributing choked orifices (or a screen) across the engine face to obtain a constant inflow velocity.

\section{Concluding Remarks}

To gain some insight into how the engineaircraft distortion compatibility problem will be handled in the near future, personnel from several engine and aircraft companies were contacted. It was generally accepted that, for the forseeable future, compatibility will remain an empirical art, to be defined by the deterministic method applied to a 40-48 tube dynamic rake at the engine face to measure distortion, and by testing the engine with screens to determine its distortion tolerance. That doesn't mean, however, that there aren't places for the other techniques previously discussed. More complex parallel compressor models are being developed to guide compression system design and development for improved distortion tolerance. Statistical distortion treatment was proposed for use in the early, small-scale inlet development to reduce cost of instrumentation and data reduction.

As a result of their reduced costs and increased capability, digital computers appear to be replacing analog and hybrid types for deterministic data reduction. Their superior flexibility was a prime reason for their popularity. On-line instantaneous distortion calculation was not considered crucial, primarily because of the difficulty of debugging the system including bad transducers in real time. In general, the major contributions to understanding the effects of instantaneous distortion on engine stability were made prior to the mid seventies, and recent efforts have primarily contributed reliability and convenience in implementing the necessary instrumentation and data reduction.

\section{References}

1. Pearson, H., and McKenzie, A.B., "Wakes in Axial Compressors," Journal of the Roya 1 Aeronautical Society, Vol. 63, July 1959, pp. 415-416.

2. Reid, C., "The Response of Axial Flow Compressors to Intake Flow Distortion," ASME Paper No. 69-GT-29, Mar. 1969.

3. Braithwaite, W. M., Graber, E. J., and Mehalic, C. M., "The Effects of Inlet Temperature and Pressure Distortion on Turbojet Performance," NASA TM X-71431, Nov. 1973.

4. Evans, D. G., deBogdan, C. E., Soeder, R. H., and Pleban, E. J., "Some Comparisons of the Flow Characteristics of a Turbofan Compressor System With and Without Inlet Pressure Distortion," NASA TM X-71574, July 1974.
5. Kimzey, W. F., and Ellis, S. H., "Supersonic Inlet Simulator - A Tool for Simulation of Realistic Engine Entry Flow Conditions, "SAE Paper No. 740824, Oct. 1974.

6. Plourde, G. A., and Brimelow, B., "Pressure Fluctuations Cause Compressor Instability," Airframe/Propulsion Compatibility Symposium, AFAPL-TR-69-103, June 1969, pp. 567-603.

7. Bowditch, D. N., Coltrin, R. E., Sanders, B. W., Sorensen, N. E., and Wasserbauer, J. F., "Supersonic Cruise Inlets," Aircraft Propulsion, NASA SP-259, Nov. 1970, pp. 283-312.

8. Czysz, P., "A Data System Concept for the Acquisition, Identification, and Analys is of Critical Time Variant Pressure Parameters for Engine/Airframe Compatibility Programs," AIAA Paper No. 70-594, May 1970.

9. Costakis, W., "Analog Computer Implementation of Four Instantaneous Distortion Indices," NASA TM X-2993, Mar. 1974.

10. Sedlock, 0., "Dynadec Operational Manual," AFFOL TM-74-32-FXM, Feb. 1974.

11. Koch, K. E., and Rees, R. L., "Analys is of Pressure Distortion Testing," NASA CR-2766, Dec. 1976.

12. Burstadt, P. L., and Wenzel, L. M., "A Method to Account for Variation of Average Compressor Inlet Pressure During Instantaneous Distortion Analys is," AIAA Paper No. 76-703, Ju7y 1976.

13. Jacocks, J. L., and Knejle, K. R., "Statistical Prediction of Maximum Time Variant Inlet Distortion Levels," AEDC-TR-74-121 (AD-A004104), Jan. 1975.

14. Melick, H. C., Ybarra, A. H., Bencze, D. P. "Est imating Maximum Instantaneous Distortion from Inlet Total Pressure RMS and PSD Measurements," NASA TM X-73145, June 1976.

15. Motycka, D. L., "Determination of Maximum Expected Instantaneous Distortion Patterns from Statistical Properties of Inlet Pressure Data, "A IAA Paper No. 76-705, July 1976.

16. Stevens, C. H., Oliphant, R. C., and Spong, E. D., "Evaluation of Statistical Method for Determining Peak Inlet Flow Distortion Using F-15 and F-18 Data," AIAA Paper No. 80-1109, June 1980.

17. Sanders, M. E., "An Evaluation of Statistical Methods for Prediction of Maximum Time-Variant Inlet Total Pressure Distortion, " A IAA Paper No. 80-1110, June 1980.

18. Forner, J. A., and Manter, J. M., "Prediction of Cruise Missile Inlet Peak Instantaneous Distortion Patterns from Steady State and Turbulence Data Using a Statistical Technique," A IAA Paper 82-1085, June 1982.

19. Hall, G. R., "A Criterion for Prediction of Airframe Integration Effects on Inlet Stability with Application to Advanced Fighter A ircraft," A irframe/Propulsion Interference, AGARD CP-150, Mar. 1975.

20. Behal, J. A., Belgen, M. H., and Simons, 0. E., "Wind Tunnel/Flight Test Data Correlation, Final Report," AFFOL-TR-71-105, Oct. 1971.

21. Soeder, R. H., and Bobula, G. A., "Effect of Steady-State Pressure Distortion on Flow Characteristics Entering a Turbofan Engine," NASA TM-79134, Apr. 1979. 


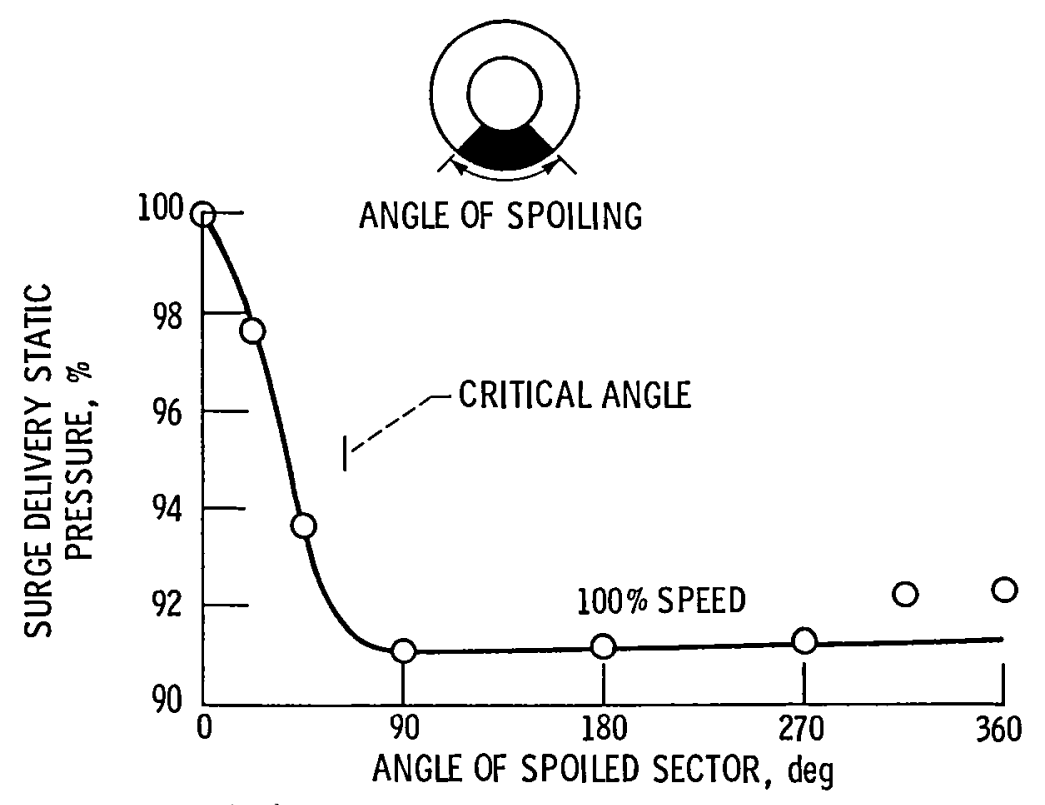

Figure 1. - Effect of varying circumferential angle of spoiling on compressor.

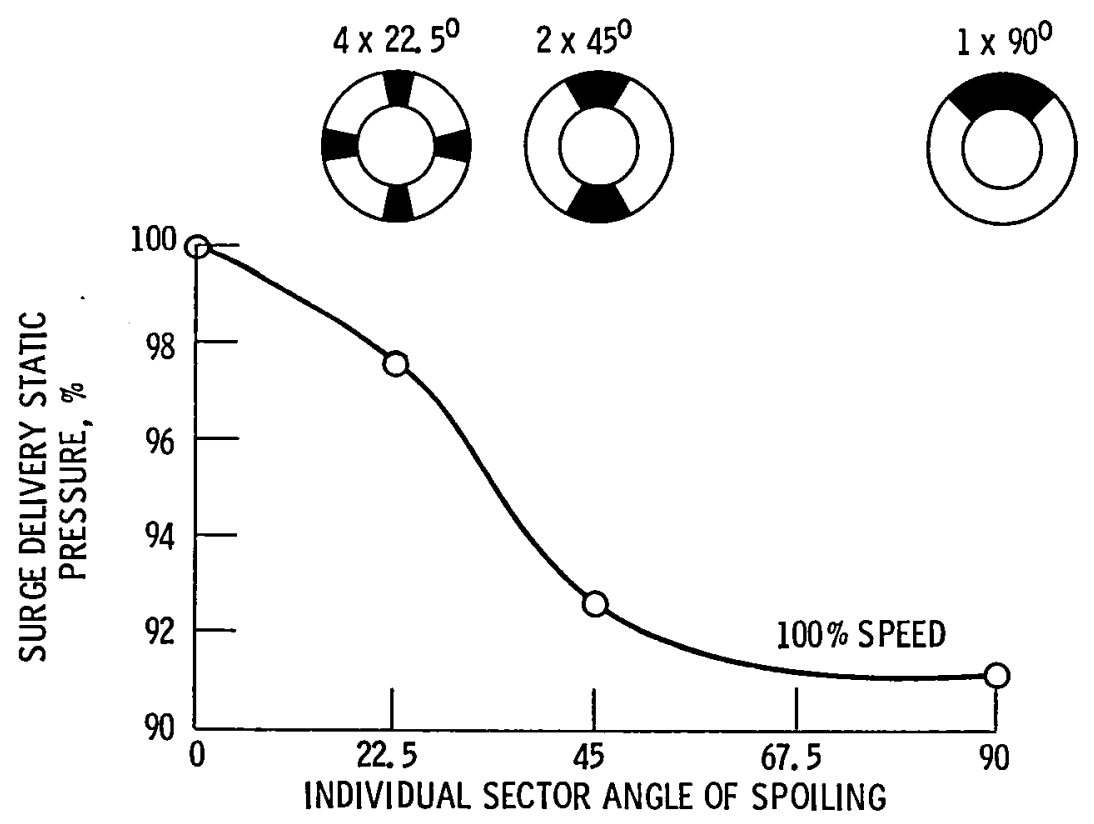

Figure 2. - Effect of dividing spoiled sector angle on compressor. 


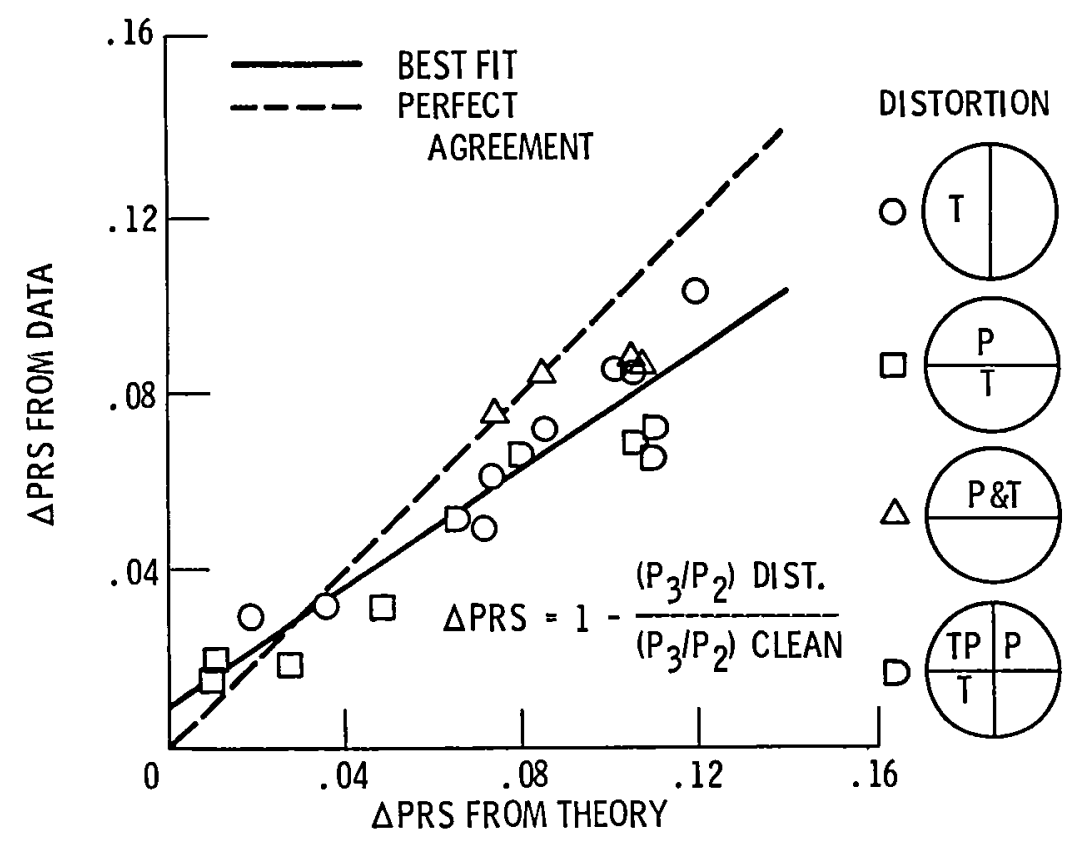

Figure 3. - Comparison between actual and predicted loss in stall pressure ratio using parallel compressor theory.

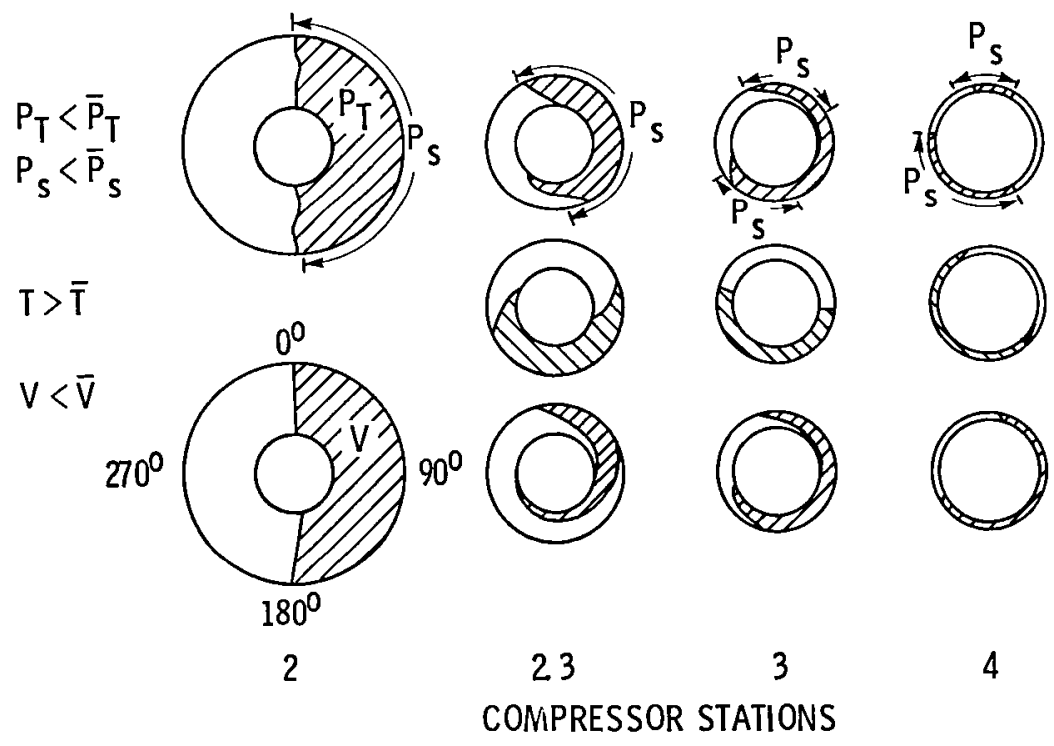

Figure 4. - Spacial variation of distorted sectors, looking upstream (clockwise rotor rotation) in a low bypass turbofan engine. 
COMPLEX COMPRESSOR MODELS

FEATURES

- over 30 parallel compressors

- Radial (2D) flOW efFects (BYPaSS Ratio)

- DYNAMIC RESPONSE TO DYNAMIC DISTORTION

- ENGINE INDUCED FLOW REDISTRIBUTION

- CAVITY CROSSFLOWS

- VARIABLE GEOMETRY COMPRESSOR

CHARACTERISTICS

- PREDICTS MANY QUALITATIVE EFFECTS

- MORE TOLERANT CONFIGURATIONS

- cRItICAL STAGE

- PROVIDES a tOOL tO GUIDE DEVELOPMENT

- NOT ALWAYS ACCURATE QUANTITATIVE PREDICTION

Figure 5. - Complex compressor models.

- STATUS

-PARALLEL COMPRESSOR THEORY

- CONTRIBUTES TO UNDERSTANDING OF DISTORTION EFFECTS

- CAN GUIDE EMPERICAL PROGRAM

- COMPLEX MODELS REQUIRED FOR TURBOFAN COMPRESSION SYSTEMS

- INTERACTION OF RADIAL AND CIRCUMFERENTIAL DISTORTION NOT WELL UNDERSTOOD

-REMATCH OF DUAL ROTOR ENGINES EFFECTS RESPONSE

- CONCLUSION

- CURRENT COMPATABILITY PROGRAMS MUST USE EMPERICAL PARAMETERS SUCH AS $K_{\theta}, K_{r}, K_{D}$, IDR, IDC ETC.

Figure 6. - Turbine engine distortion response. 

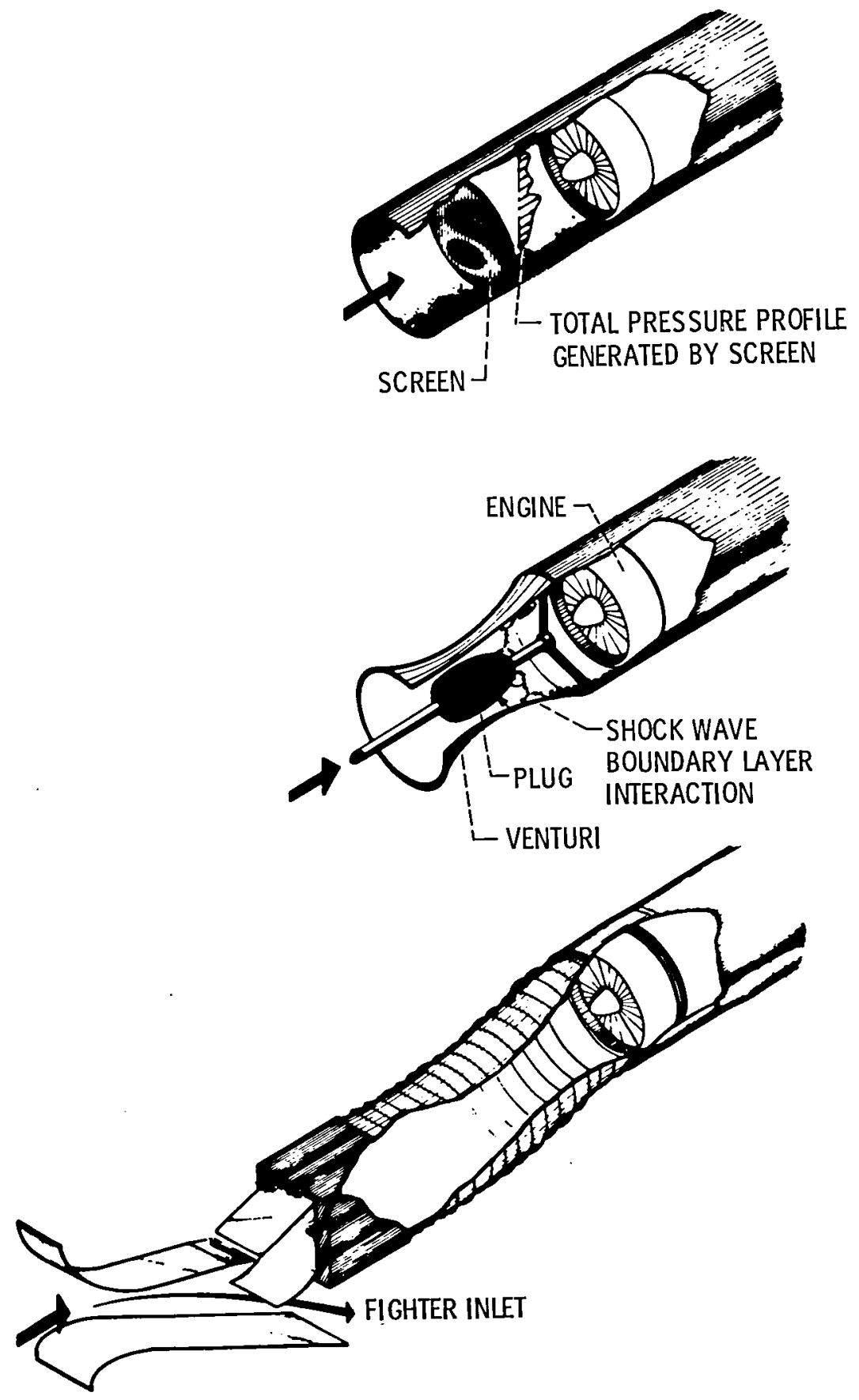

Figure 7. - Inlet distortion simulators. 


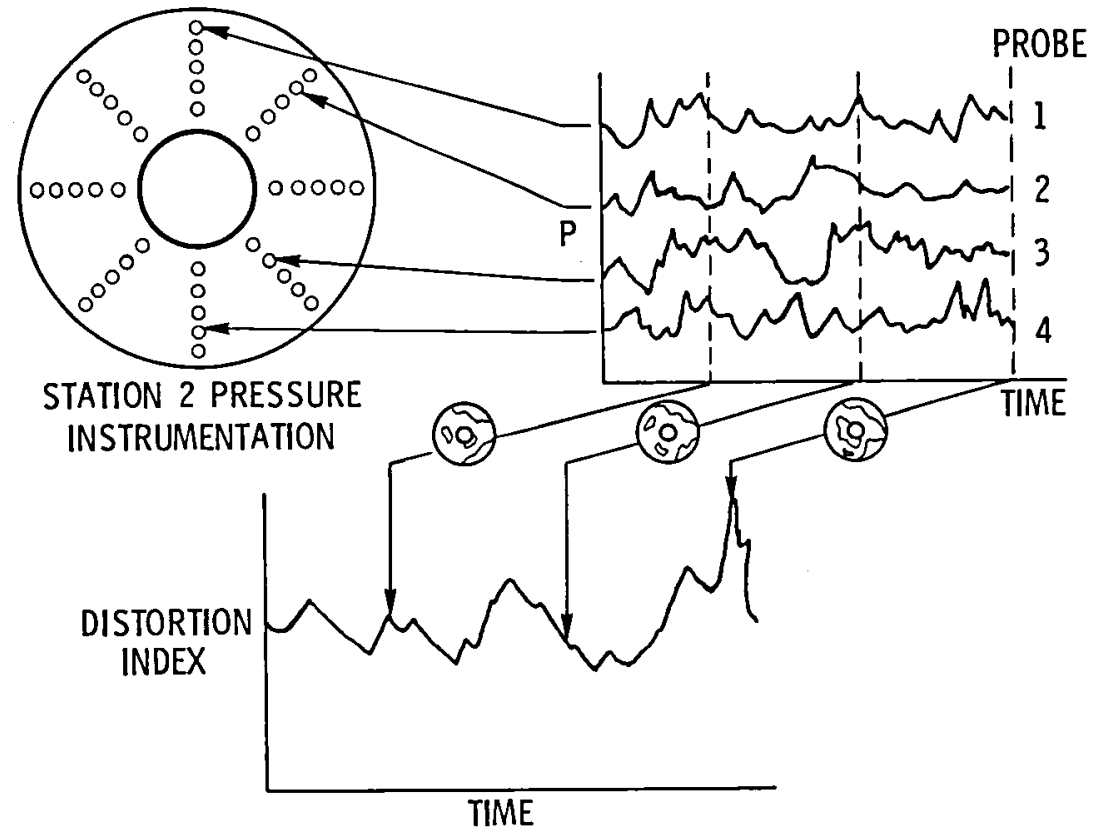

Figure 8. - Instantaneous distortion index. 
(a)
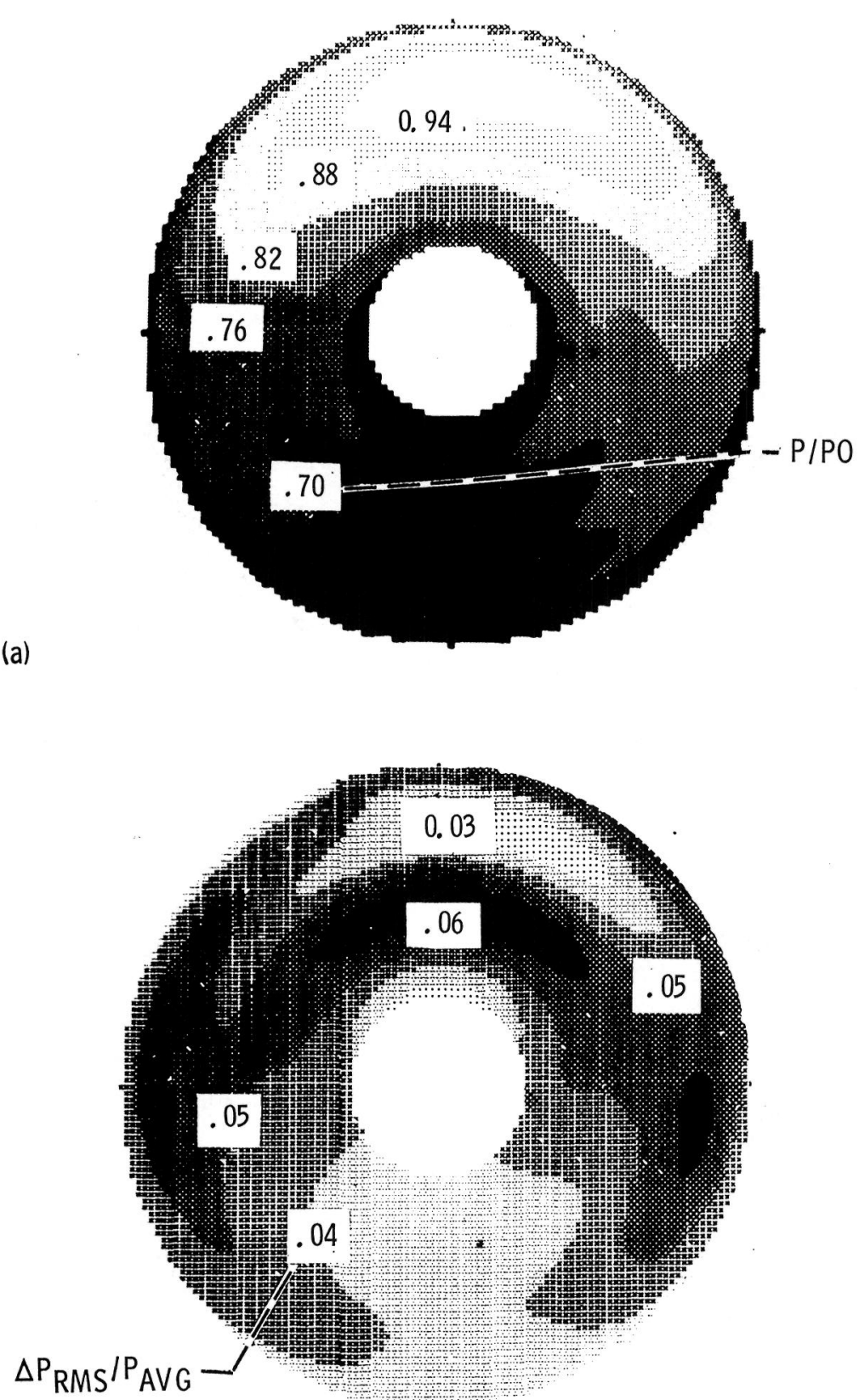

(b)

(a) Steady state, $\mathrm{P}_{A V G} / \mathrm{P}_{0}=0.769 ; \Delta \mathrm{P} / \mathrm{P}_{\mathrm{AVG}}=0.178$

(b) Dynamic, $\left(\triangle \mathrm{P}_{\mathrm{RMS}}\right)_{\mathrm{AVG}}{ }^{\prime \mathrm{P}_{A V G}}=0.046$.

Figure 9. - Steady state and turbulent distortion contours. Mach No. 2.6; angle of attack, $5^{0}$. 


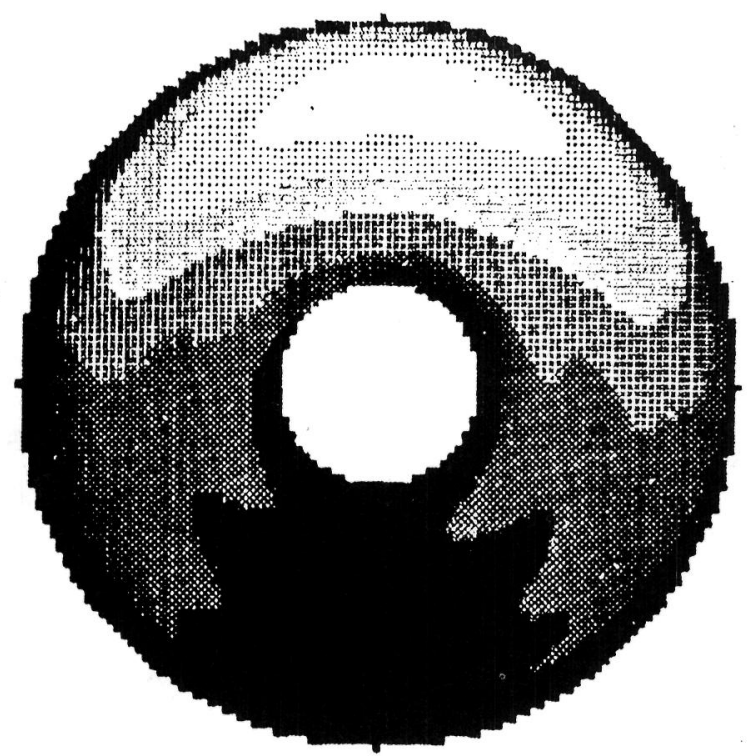

0.10

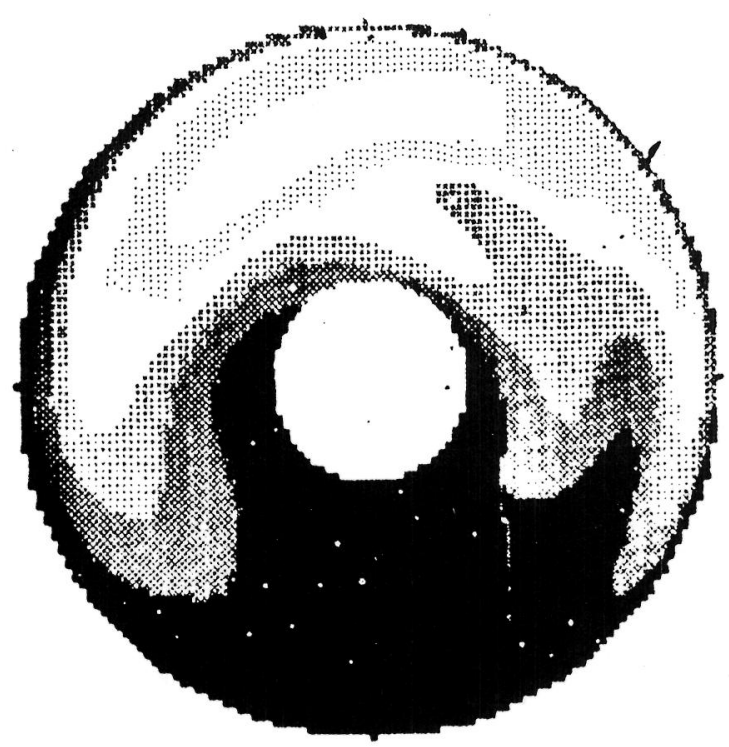

0.155

(a) Steady state.

(b) Maximum instantaneous.

Figure 10. - Steady state and maximum instantaneous distortion contours. Mach No. 2.6; angle of attack, $5^{0}$, di stortion parameter, $\triangle \mathrm{PRS}$. 


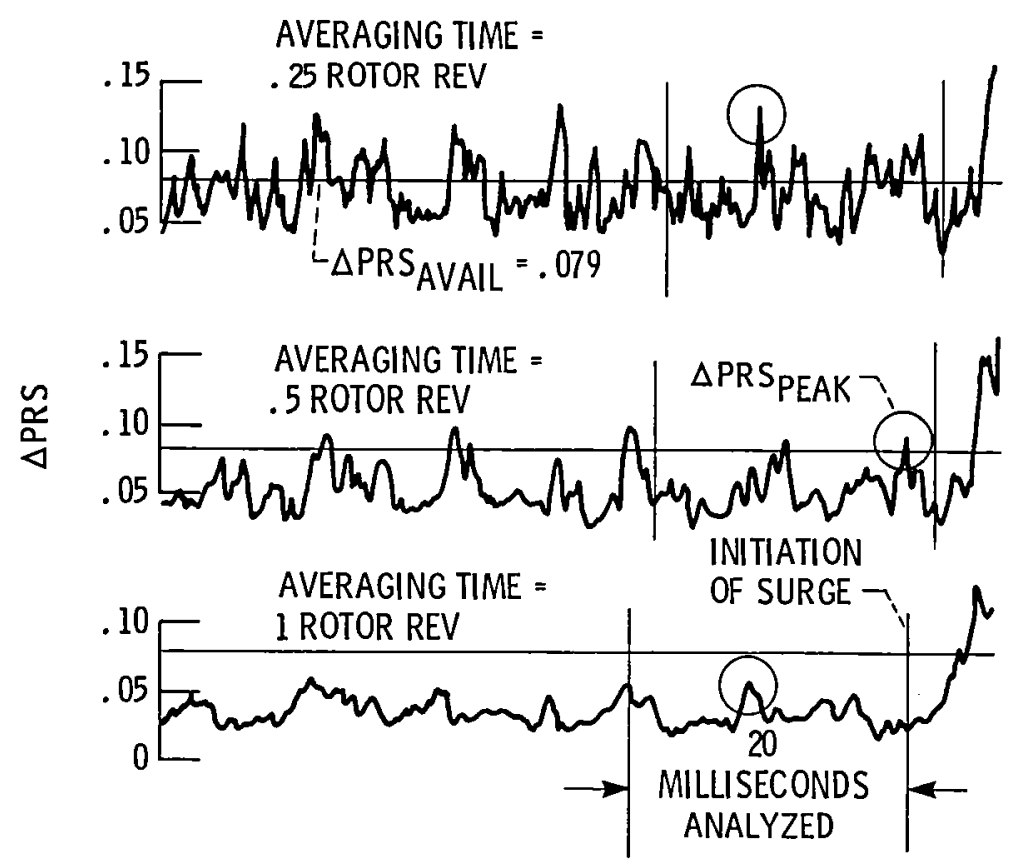

Figure 11. - Evaluation of appropriate averaging time to predict dynamic distortion causing stall.

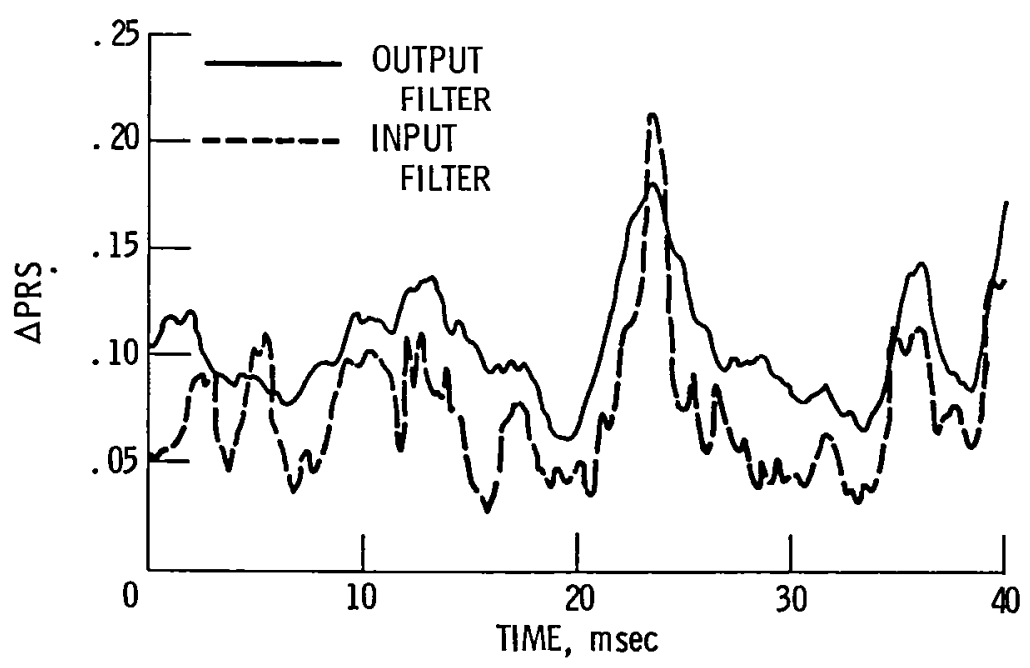

Figure 12 - Comparison of input versus output filtering of $\triangle \mathrm{PRS}_{\mathrm{CALC}}$. 


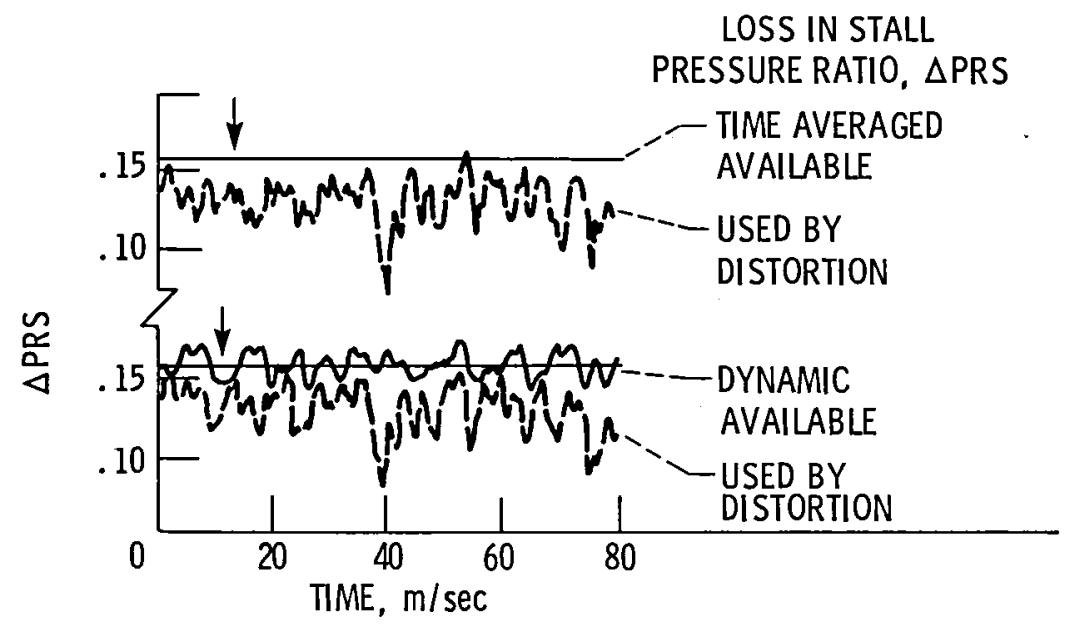

Figure 13. - Effect of accounting for time variation of average compressor inlet pressure during instantaneous distortion analysis.

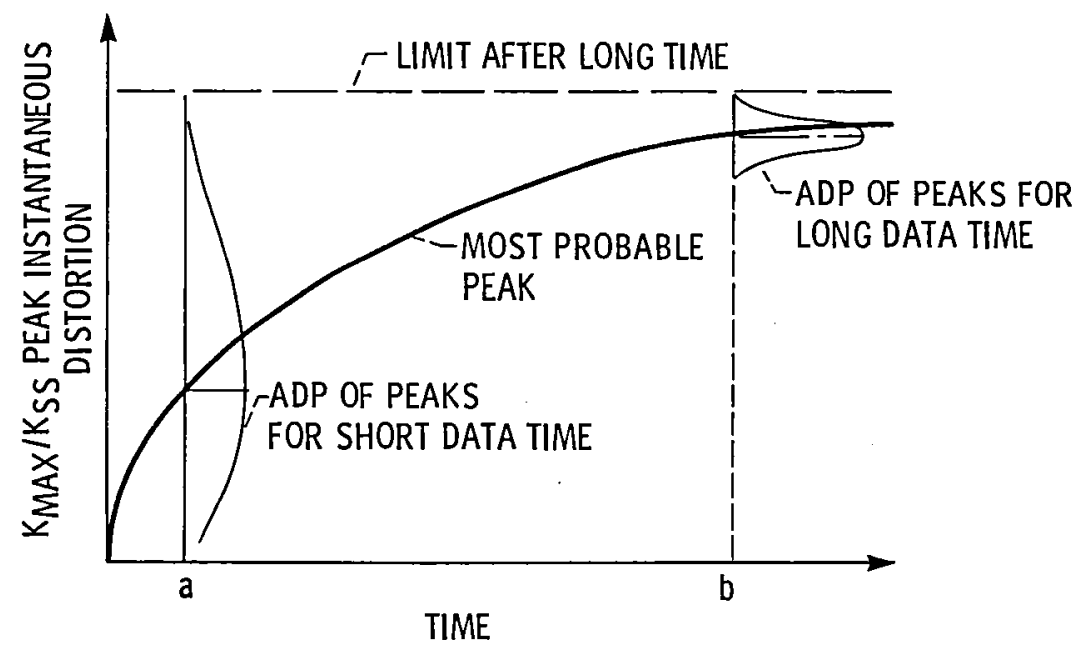

Figure 14 - Effect of data acquisition time on peak distortion. 


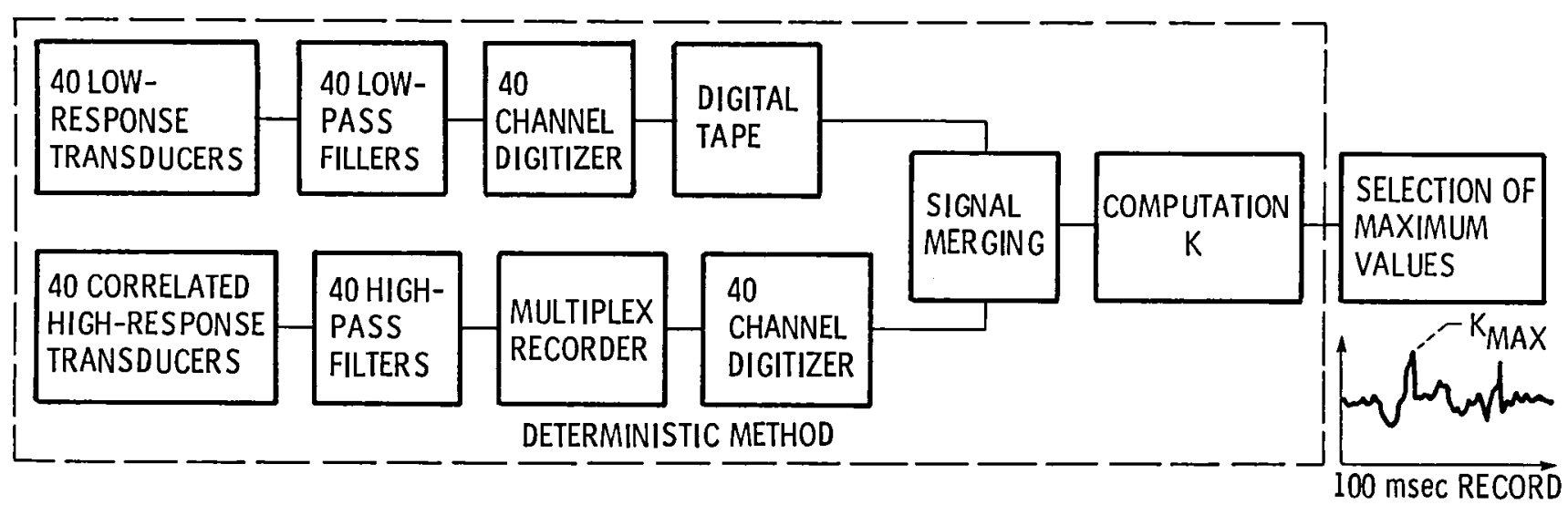

Figure 15. - Deterministic method for processing time-variant distortion data.

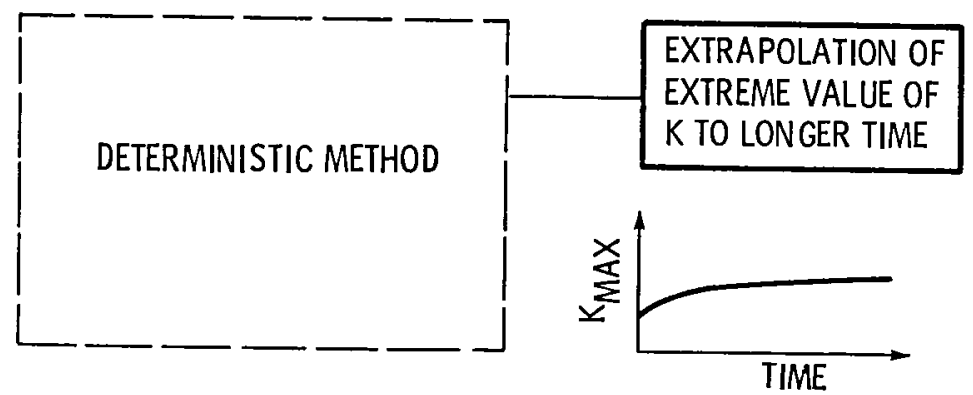

Figure 16. - Jacocks statistical method for processing time-variant distortion data.

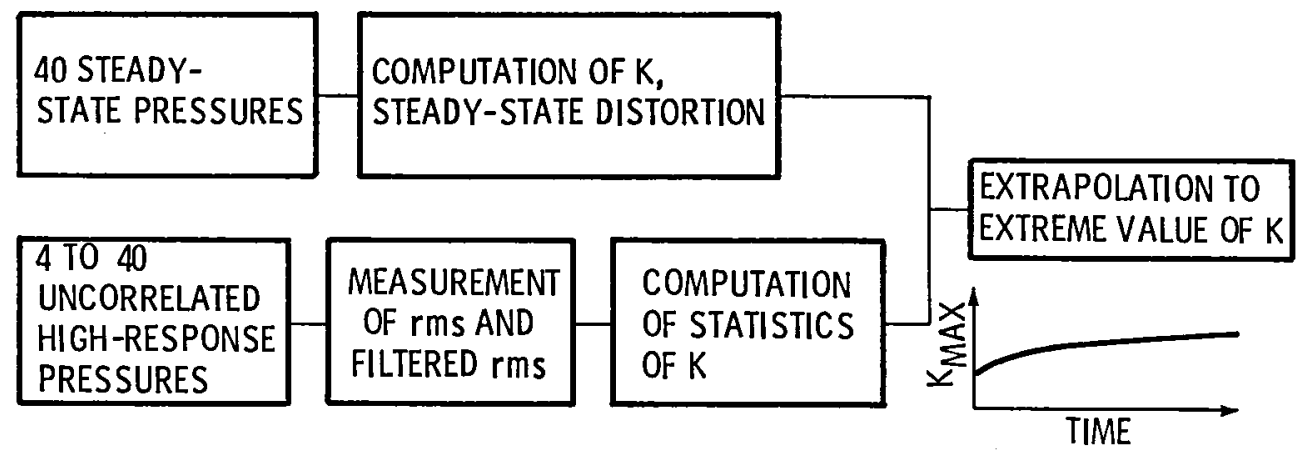

Figure 17. - Melick statistical method for processing time-variant distortion data. 


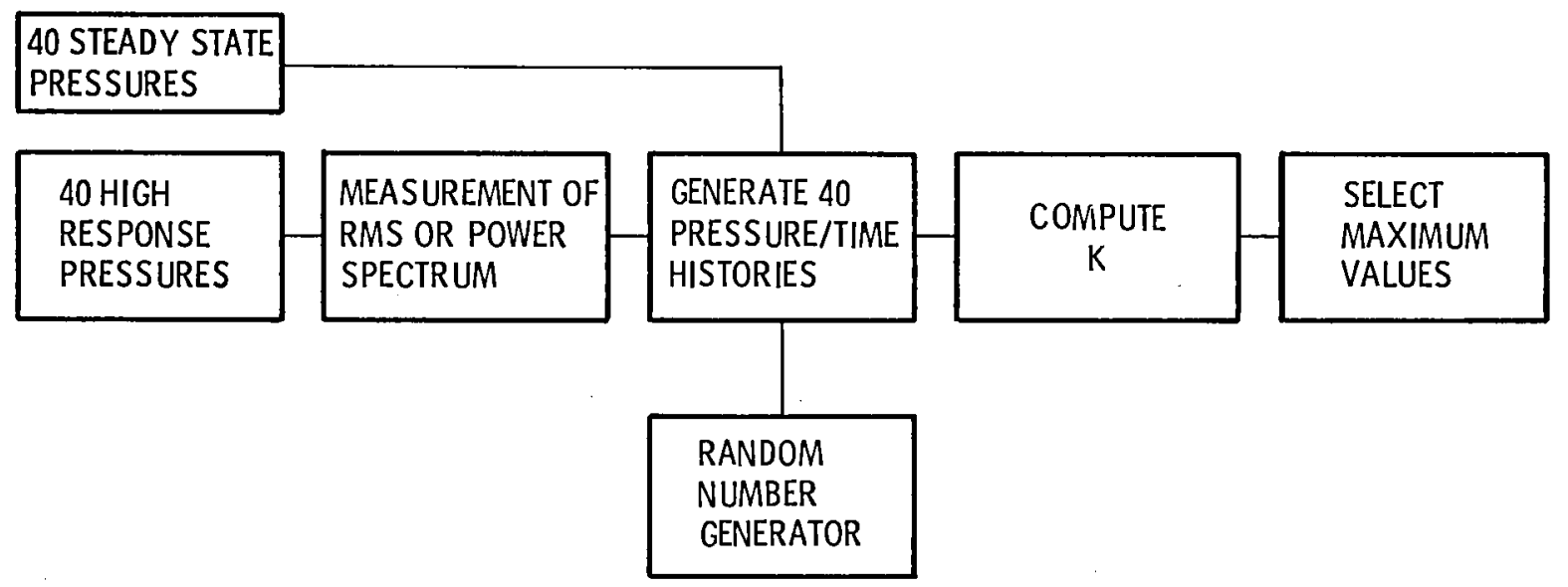

Figure 18. - Motycka/Stevens statistical method for processing time-variant distortion data. 


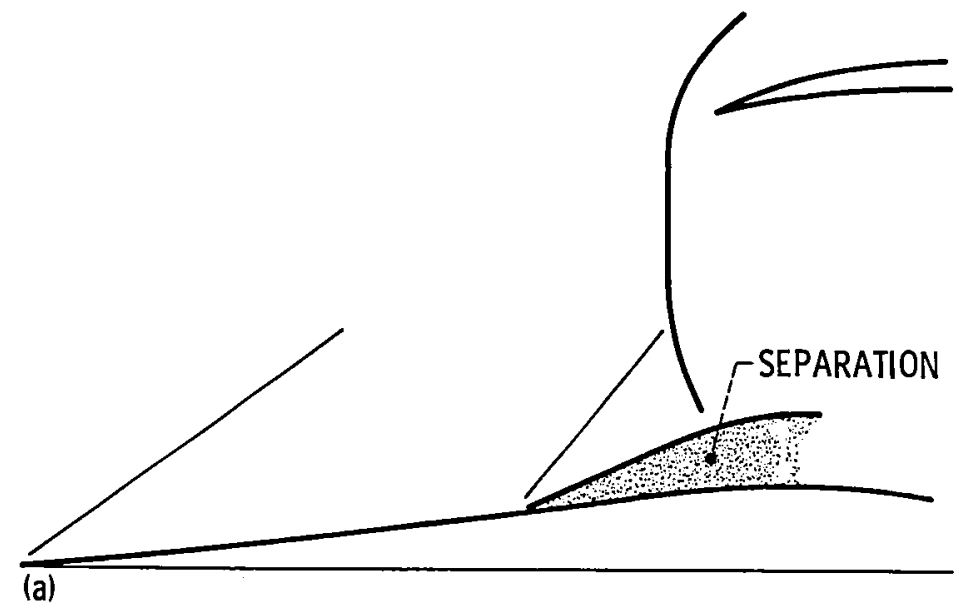

(b)

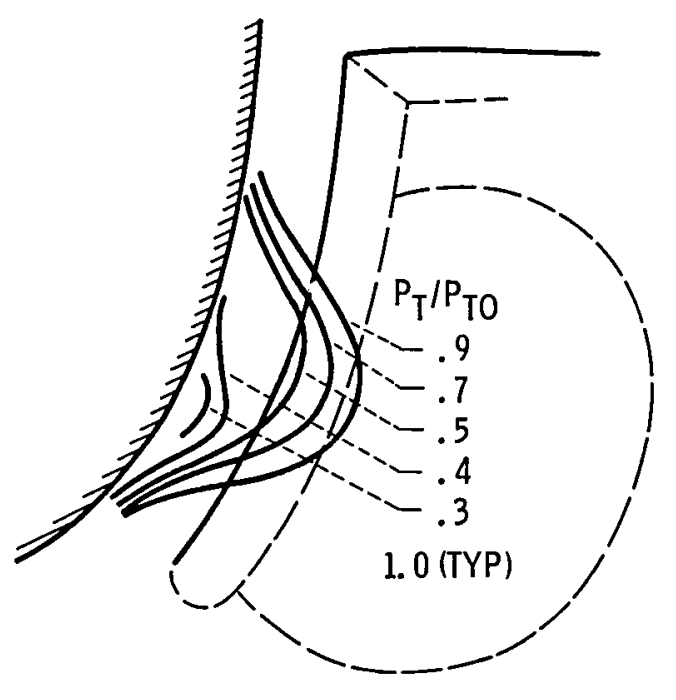

(c)

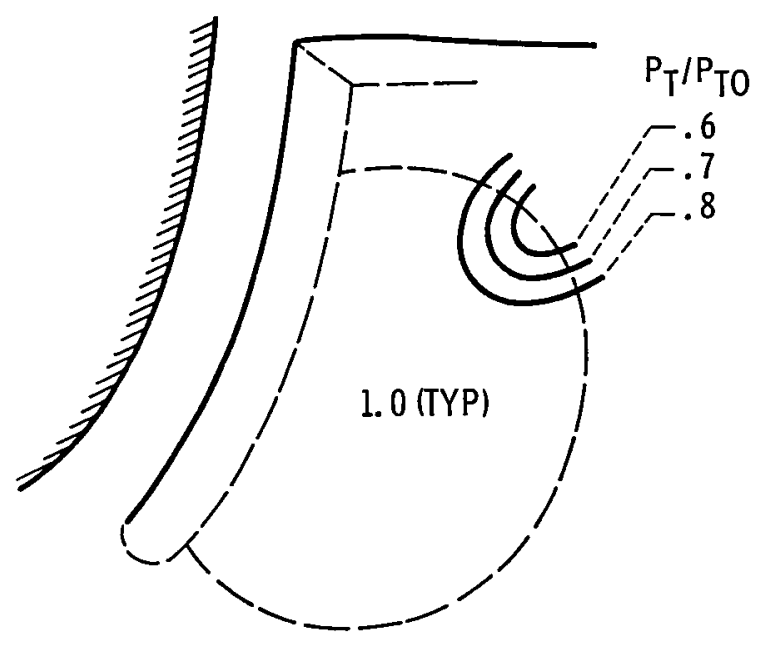

(a) Terminal shock boundary layer interaction.

(b) Local separation or thickening of boundary layer.

(c) Vortex ingestion.

Figure 19. - Sources of inlet distortion. 
- REYNOLDS NUMBER

- ADJUST DIVERTER HEIGHT FOR BOUNDARY LÀYER THICKNESS

- AJUST BLEED FOR PROPER BOUNDARY LAYER CONTROL

- SLIGHT DISTORTION INCREASE AT LOWER RN IF NO LIMIT ENCOUNTERED

- ANALYSIS CAN BE USED TO ASSESS BOUNDARY LAYER THICKNESS, BLEED, SEPARATION, ETC.

- LINEAR FREQUENCY SCALING OF DYNAMIC DISTORTION SPECTRA

- ENGINE INDUCES NEARLY CONSTANT VELOCITY ACROSS ENGINE FACE

Figure 20. - Inlet distortion testing.

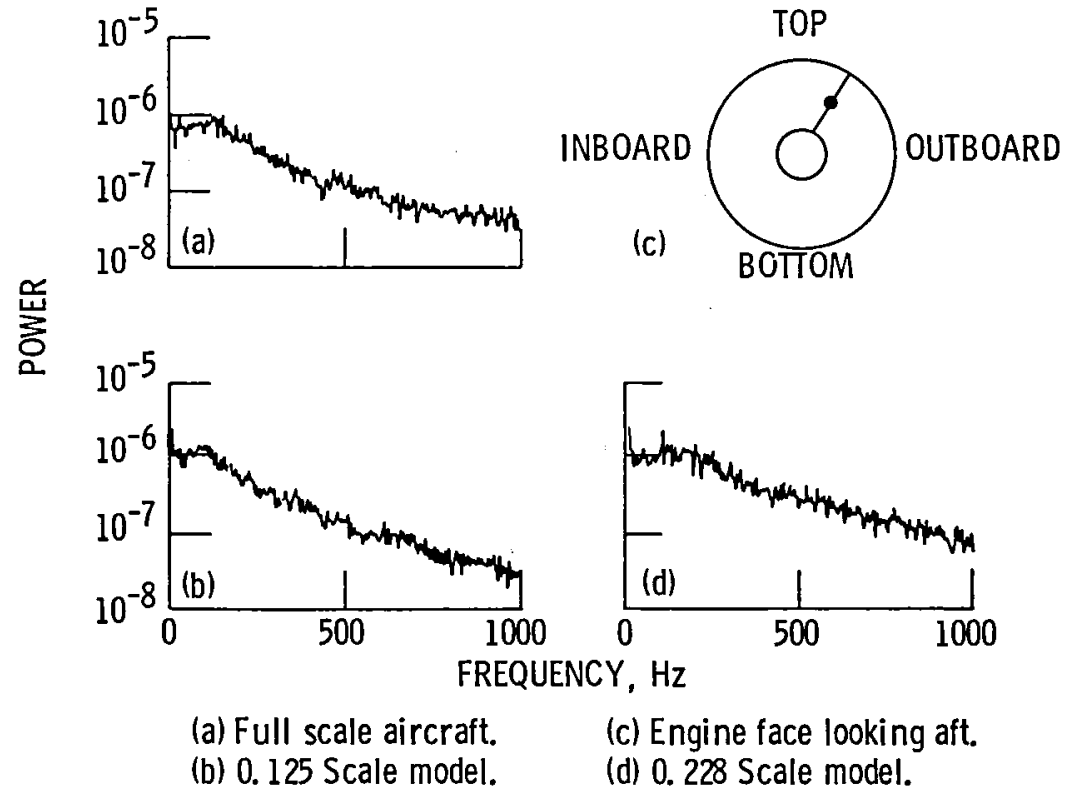

Figure 21. - Linearly scaled power spectral density, RA-5 compressor face. 

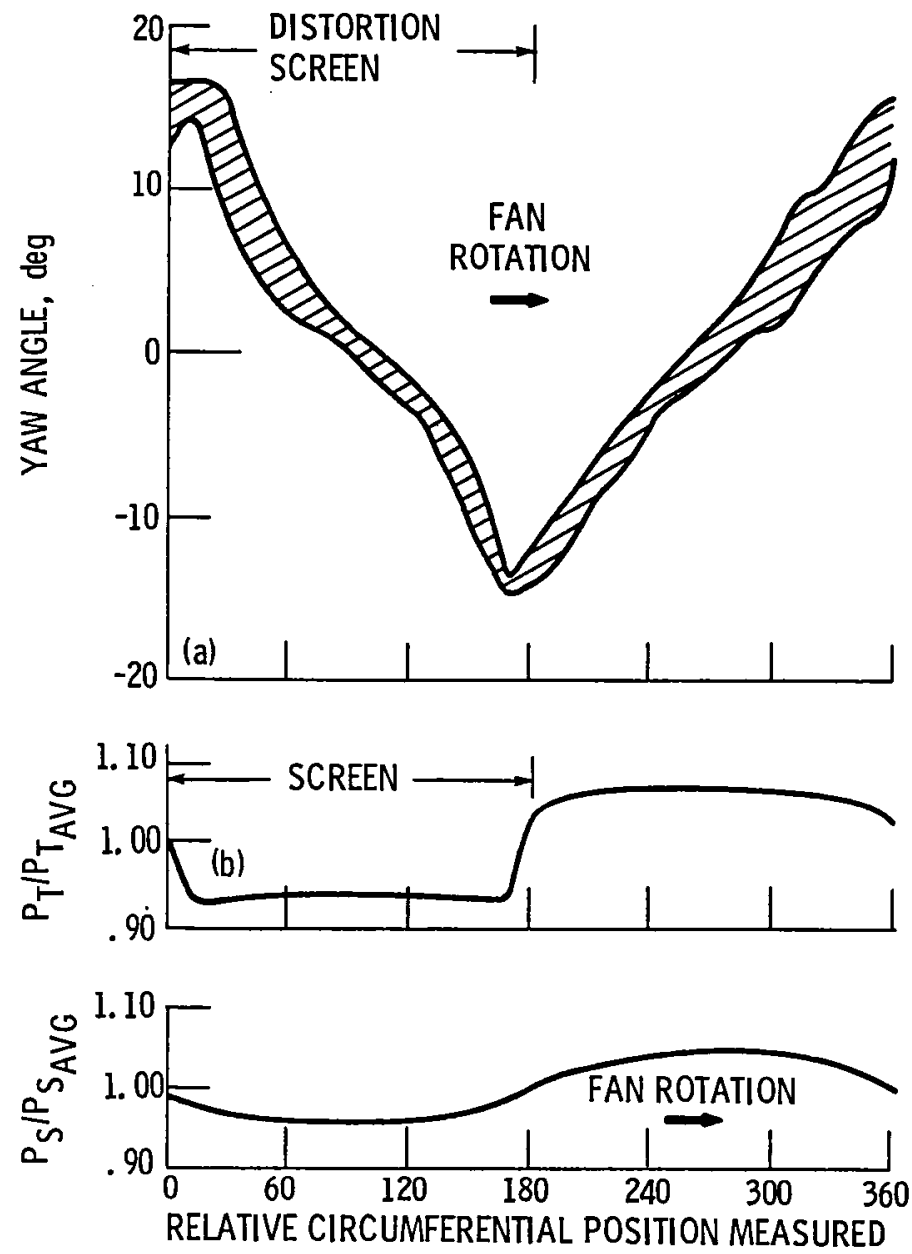

IN THE DIRECTION OF ROTATION, deg
(a) Flow angle.
(b) Total pressure.
(c) Static pressure.

Figure 22 - Engine face conditions for a screen distortion. 



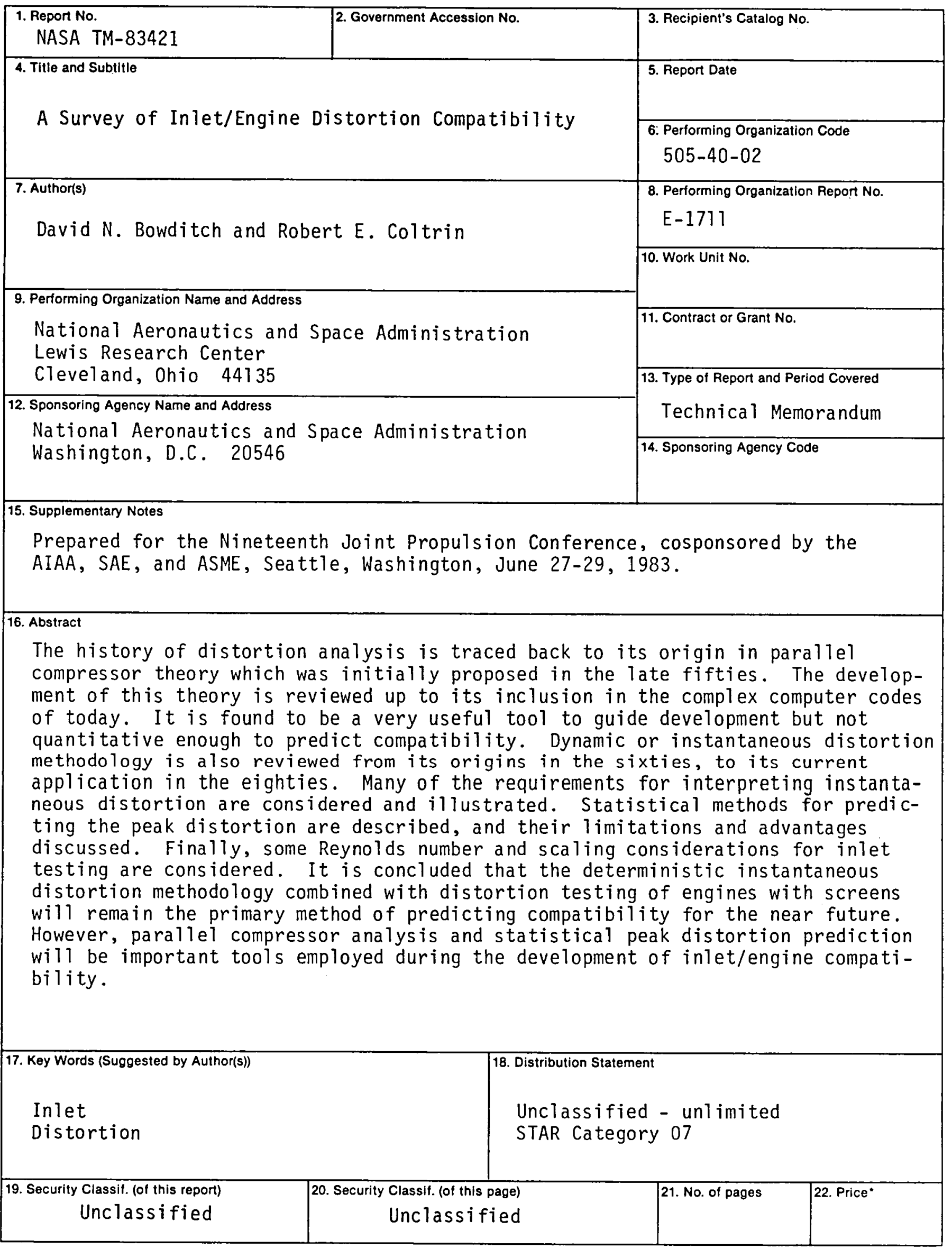

*For sale by the National Technical Information Service, Springfield, Virginia 22161 
National Aeronautics and Space Administration

Washington, D. $\dot{C}$.

20546

Official Business

Penaliy for Private Use, $\mathbf{5 3 0 0}$
SPECIAL FOURTH CLASS MAIL BOOK

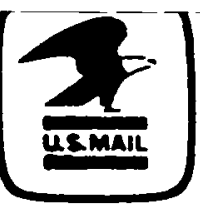

Postage and Fees Paid National Aeronautics and Space Administration NASA-451 